\title{
P-183
}

\section{The Potential of Thiosulfinates in Allium Savatium as Bioinhibitor for Controlled Release Fertilizer Application}

\author{
Nur Kamila Ramli ${ }^{1, *}$, Nurlidia Mansor, Sity Juaeiriah Samsudin and Zahid Majeed \\ Chemical Engineering Department, Universiti Teknologi Petronas, Bandar Seri Iskandar, 31750 Tronoh, Perak Darul \\ Ridzuan, Malaysia; E-mail: nurkamila_r@yahoo.com
}

Urea is an important source of ammonia $\left(\mathrm{NH}_{3}\right)$ for crops and various agricultural usages. However, $40 \%$ of the total $\mathrm{NH}_{3}$ is released to the atmosphere due its hydrolysis process. Several attempts have been made in controlling ammonia evolution from urea including the usage of urease inhibitors. This is one of the possible ways to reduce $\mathrm{NH}_{3}$ emissions to the atmosphere after urea fertilizer application, especially when urea is surface-applied. These compounds can retard the hydrolysis of urea by inhibiting the urease enzyme in the soil. Many chemical compounds have been tested and shown inhibitory process against the urease enzyme. However, few are used commercially and most investigated inhibitors are chemical based and toxic. Thus, this research will study about the thiosulfinates compound in garlic extract as a potential bioinhibitor for fertilizer application. Previous studies have shown that the loss of urease activity was found to be directly proportional to alk(en)yl thiosulfinates (TS) content in the garlic extract. There is evidence by data provided that TS is the actual inhibiting agents in the garlic extract. The inhibition process is attributed to the reaction of TS compound with the SH-group that is found in the active site of the urease enzyme. Studies indicate that inhibition by garlic extract is irreversible and incubation time-dependent. Thus, the usage of Allium savatium as a green and environmental friendly product should be considered to replace the current chemical based bioinhibitor.

Keywords: Garlic extract, alk(en)yl thiosulfinates. 